Trends in Contemporary Art Discourse: Using Topic Models to Analyze 25 years of Professional Art Criticism
(C) The Author(s) 2018

Reprints and permissions: sagepub.co.uk/journalsPermissions.nav DOI: |0.1 I77/I7499755|876486 | journals.sagepub.com/home/cus

\author{
Henk Roose \\ Ghent University, Belgium
}

Willem Roose

Ghent University, Belgium

\title{
Stijn Daenekindt
}

Ghent University, Belgium; and Erasmus University Rotterdam, Netherlands

\begin{abstract}
In this article, we use topic modeling to systematically explore topics discussed in contemporary art criticism. Analyzing 6965 articles published between I99I and 2015 in Frieze, a leading art magazine, we find a plurality of topics characterizing professional discourse on contemporary art. Not surprisingly, media- or genre-specific topics such as film/cinema, photography, sculpture/ installations, etc. emerge. Interestingly, extra-artistic topics also characterize contemporary art criticism: there is room for articles on new digital technology and on art and philosophy; there is also growing interest in the relationship between art and society. Our analysis shows that despite evolutions in the field of contemporary art - such as the 'social turn', in which contemporary art starts paying more attention to social forms and content - the prevalence of certain topics in contemporary art criticism has barely changed over the past 25 years. With this article, we demonstrate the unique value of topic modeling for cultural sociology: it is both a powerful computational technique to generate a bird's-eye view of a huge text corpus and a heuristic device that locates key texts for further close reading.
\end{abstract}

\section{Keywords}

Pierre Bourdieu, contemporary art, Nathalie Heinich, professional discourse, topic models

\section{Corresponding author:}

Henk Roose, Department of Sociology, Ghent University, Korte Meer 3-5, Gent 9000, Belgium.

Email: henk.roose@ugent.be 


\section{Introduction}

Specialist discourse is essential to contemporary art, as it describes and helps to interpret artifacts that would otherwise remain enigmatic or devoid of meaning to uninitiated audiences. Artists, art critics, and art scholars produce texts that serve as a mode d'emploi, mediating meaning between artwork and spectator. These texts provide means or ways to appropriate a work of art by situating it in the totality of an artist's oeuvre or by positioning it within art history or, when history is lacking, within current themes in art. In general, the sociology of art views the discourse on contemporary art as fluctuating between two opposites (Heinich, 1998; Hanquinet et al., 2014). On the one hand, there is discourse stressing formal, aesthetic aspects - in the classic Greek sense of the word, i.e. perception through the senses - relating artifacts to the internal history of the field, using categories such as originality, authenticity, expressiveness and beauty. On the other hand, there is discourse that borrows its vocabulary from domains outside the arts - e.g. psychology, philosophy, or sociology - and, hence, uses categories external to the artistic field, stressing social relevance, political/societal engagement, and participation, for example (Jackson, 2011; Martin, 2005; Milevska, 2006). Thus, discourse not only functions as an interpretative and intermediary link between specific artworks and an audience, but also provides insight into the variety of categories used within the art world to distinguish art from non-art. As such, the discourse on art reveals some of what is at stake in struggles for legitimacy, for symbolic hegemony within the art world (Bourdieu, 1996), and may disclose taken-for-granted, institutionalized standards used to justify art as being art (Boltanski and Thévenot, 1991; Danto, 2001).

The central aim of this article is to empirically analyze the plurality of topics in the professional discourse on contemporary art, discuss their evolution over time, and explore their inter-relation. Therefore, we use topic modeling on articles published from 1991-2015 in Frieze, a leading magazine on contemporary art. Topic modeling refers to a group of inductive statistical techniques that are able to uncover thematic structures in large text corpora (Blei et al., 2003; Mohr and Bogdanov, 2013). Its algorithms look for co-occurrences of words in documents and generate lists of words that have a high probability of co-occurring. Thus, this article adds to the expanding literature on how topic models can be deployed to quantitatively analyze huge corpora of texts and disclose meaning structures. Although topic modeling is still only marginally used in cultural sociology and - as far as we can see - is absent in the sociology of art, we demonstrate that it provides a 'valuable method for identifying the linguistic contexts that surround social institutions' (DiMaggio et al., 2013: 570).

We contribute in several ways to the sociology of art. First, our work represents one of the first attempts to systematically explore and describe (changes in) features of professional discourse within the field of contemporary art (cf. Martin, 2005). Our analysis explores the kind of themes art critics talk about when they discuss contemporary art. For example, does beauty play a role in contemporary art appreciation? Are the artifact and its formal characteristics still important or do they increasingly have to share the stage with 'the social' in art, both in terms of its ideologically charged content and in the way it engages its audience (Bourriaud, 1998)? Can the 
relational and participatory character of contemporary art - as illustrated by the emergence of performances and happenings - also be traced in the discursive practices of professional intermediaries? Is the political commitment of art and artists important (cf. Alexander, 2017)?

Second, and relatedly, by systematically describing professional discourse in one of the leading magazines on contemporary art, we are able to infuse social scientific discussions with systematic empirical material. Is there some kind of lingua franca within the art system centering on core topics that shape a coherent justificatory regime? How do autonomous and heteronomous criteria relate to each other (cf. Bourdieu, 1996)? Bourdieu insists that artists who do not play by the rules of the game will be denounced. He considers commercial success and the social to be alien - or heteronomous - to the logics of the artistic field, which thrives on attaining symbolic recognition by peers. However, the straightforward opposition between autonomous and heteronomous principles of justification may need revision when considered through the lens of contemporary art, which increasingly uses social and/or political - and hence, heteronomous - principles to justify art as being art. In this way, our analysis explores whether prioritizing subject matter through highlighting form and technique still dominates recent art discourse or whether societal and/or political engagement of contemporary art infuses discourse as well. By addressing these questions, our analysis can be seen as a somewhat late response to Zolberg's complaint (1990) when she lamented the remarkable neglect of the beaux arts within cultural sociology.

\section{Theoretical Background}

\section{Sociology and Contemporary Art}

Bourdieu is one of the most influential art sociologists. He argued that 'la sociologie et l'art ne font pas bon ménage [sociology and art do not make good bedfellows]' (Bourdieu, 1980: 207). Art is the domain par excellence of the denial of the social, because the field of art generates a sociologically uninformed illusio that artistic production is free from social-structural constraints and that artists are inspired geniuses. Bourdieu's aesthetic theory critically unmasks false social constructions and illusionary self-definitions in the art world by showing how social structures shape both consumption and production of culture. This sociology of culture is mainly concerned with the way structure influences culture. Other influential examples of this approach are White and White's (1965) study of the institutional changes in the French painting world; Becker's (1982) approach that regards artistic production as a result of a system of collective action rather than individual artists; and Peterson and Anand's (2004) production of culture perspective that focuses on the way elements of symbolic culture are shaped by the systems in which they are produced.

However valuable these approaches are for understanding the social organization of cultural production in our society, they do not disclose what actors in cultural fields consider the important themes that guide their actions. In other words, sociology of culture tends to neglect the day-to-day cultural practices of meaning-making of the actors involved in these fields. Indeed, what has characterized the sociology of art 
since the 1970s is 'a skepticism towards the worldview of artists and the art worlds they inhabit' (de la Fuente, 2007: 412). In contrast to the alleged 'sociologism' of Bourdieusian orthodoxy, several scholars have stressed the relative autonomy of culture in relation to the social-structural configurations in society. Thus, we focus on processes of meaning-making by actors within the art world itself and, in doing so, join an emerging stream of research that sets out to broaden the sociological frame to include the artwork, its meaning, and its aesthetics (cf. de la Fuente, 2007; Hanquinet and Savage, 2016; Zolberg, 2015).

The emphasis on the artworks themselves, however, stands in contradiction to the nature of contemporary art, which abandons the modernist primacy of formal aesthetics to focus on the conceptual side of artworks. While artworks in classical and modern art are 'readable' as symbols or signs, contemporary art very often relies more on what is not directly visible. Thus, in contemporary art, focusing solely on art objects is often problematic, since meaning is not only inscribed in the materiality of the artifact, but also in the discourse surrounding the object. As an artist who opened the way to contemporary art, Duchamp famously spoke out against 'retinal art' and emphasized art's conceptual and intellectual dimensions. His readymades and conceptual works are not intended to please the senses but are 'in the service of the mind' (Duchamp as quoted in Arnason and Prather, 1998: 274). Indeed, focusing only on aesthetics leaves the sociology of art blind to the nature of art in the 'post-Duchamp' era. 'Art sociologists who limit themselves to imagery or material dimension of paintings and leave the accompanying discourse out ignore the specific character of art and the art world' (Heinich, 1998: 46). Therefore, the sociology of art should pay attention to the discourse surrounding the artwork.

While social scientists have always been active in making sense of the art of their time, a sociological theorization of contemporary art is currently lacking (Alexander, 2003; Inglis and Hughson, 2005; Tanner, 2003). Notable exceptions are Laermans (2015) on contemporary dance, and Cools and Gielen (2014) on art, dance, ethics, and politics. Heinich's work also provides a sociological understanding of contemporary art in all its aspects of production, mediation, and consumption. Inspired by Heinich, we investigate discursive practices that are especially meaningful to members of the art world and take contemporary art as our main object of study.

\section{Heinich's Paradigms: Modern Versus Contemporary}

Over the course of the 20th century, a number of changes in the domain of the visual arts have taken place. The vast array of 20th-century 'isms' testifies to the immense plurality of movements, schools, and genres - all reacting to one another whilst carving their own artistic niches. Heinich reduces this enormous variety of artistic practices to a master dichotomy between 'modern' and 'contemporary'; she considers both to be guiding artistic paradigms of the 20th century (Heinich, 2014). These paradigms refer to institutionalized sets of categories and principles people can rely on to distinguish art from non-art and good from bad art. As such, a paradigm consists of systems of perception that people take for granted - and assume to be legitimate - or ways of judging artworks according to certain criteria. 
With the rise of modernism at the turn of the 20th century, the classical paradigm has been increasingly challenged: the importance of mimesis, figuration, harmony, and beauty has dwindled. Also, academic craftsmanship in the production of art has lost some of its relevance. In the modern paradigm, aesthetics is still involved, but the Kantian appreciation of beauty is replaced by other criteria such as originality, authenticity, and the power to affect. In modernism, art should affect the senses through the authentic expression of an artist's individuality. This stress on the singularity of the artistic creation promotes the autonomy of art (Taylor, 1992): trying to be original stimulates a continuous quest for novelty and transgression, pushing the boundaries of artistic expression. Moreover, transgression has come to dominate the visual arts since the Academy system based on patronage was replaced by a market system based on critics and dealers at the end of the 19th century. This institutional transformation led to a more autonomous visual art system, able to establish its own criteria for perception and appreciation and to pursue its own artistic agenda.

As noted by Elias (1993), this institutional transformation involves a shift from 'craftsmen's art', in which the taste of the patron class determines artistic production, to 'artists' art', in which artists themselves are the vanguard, introducing innovations to advance the public's taste. Thus, artistic innovation and experimentation have become the defining traits of the art system. In addition, Bourdieu's aesthetic theory acknowledges disinterestedness or the 'purposiveness without purpose' of the artist to be essential to the modern paradigm. The autonomous artistic judgment as envisioned by Bourdieu favors form over function - the 'pure' gaze or 'pure' aesthetic - and praises artistic innovation over heteronomous commercial success with easy 'functional' art. Disinterestedness is a way of 'securing the autonomy of art against the dual encroachments of the market and the state' (Bennett, 2007: 215).

Modern art is specifically concerned with its own inner logic and functioning, and thus pursues an autonomous art that avoids 'polluting' itself with concerns from other social systems (Schaeffer, 1992). In contrast, in contemporary art, the transgression of the very definition of art itself is central (Heinich, 1998, 2014). With contemporary art, the boundaries between art and life become blurred - e.g. everyday objects become art, the social and the cultural spheres merge, the traditional boundaries between highbrow and lowbrow culture vanish. Contemporary art seeks exactly the opposite of modern art: it opens art up to usurp other themes and means from domains that are external to the artistic field. For example, a Mondrian painting is inward looking. It has a thoroughly aesthetic ambition and seeks to find new ways of and procedures for painting and figuration. In contrast, when a contemporary artist like Rirkrit Tiravanija cooks for the visitors of his show (this being the work of art), he is much less concerned with aesthetics (how the work looks) than with the social role of art (bringing people together). Far from considering contemporary art as a temporal classification, Heinich reserves the term for self-reflexive art that takes extra-aesthetic elements as its building blocks and, in doing so, defines itself in contrast to modern art.

\section{The 'Social Turn': Social Form and Content in Contemporary Art}

Although Heinich provides a useful framework to capture the plurality of contemporary artistic work, her master dichotomy between modern and contemporary art fails to do 
justice to the enormous diversity of actual artistic practices. For Heinich, contemporary art is defined as one specific type of art, i.e. art that transgresses the boundaries of art itself - transgressive, internally critical art. Not all artists today, however, seek to transgress art's boundaries by refusing to produce oil on canvas or present sculptures on a pedestal. Some continue to work in artistic traditions typical of modernism. Others borrow themes and contents from non-artistic spheres such as everyday life, economy, and politics. In particular, since the nineties we have seen an explosion of practices that put the social center stage, making it the starting point for artistic maneuvers.

The social infiltrates contemporary art in various ways. We propose to make a distinction between art that incorporates social content and art that takes up social forms. 'Social content' refers to art that includes social and/or political themes; documentary art or forms of critical, political, or even activist art belong to this category. For example, we think of Johan Grimonprez's Dial H-I-S-T-O-R-Y (1997), a film about our 'mediatized' world, or Renzo Martens' movie Enjoy Poverty (2008), in which the poor in Congo are encouraged to make money out of their poverty; both movies take a strong socio-political stance. Art that makes use of social forms refers to art that aims to initiate social interactions - for example, art in which members of the audience have to engage physically with the artwork or need to cooperate or co-create the work. The art of Rirkrit Tiravanija mentioned above serves as a typical example. Interactivity and DIY are key in these social forms they are indicative of what the French art critic Nicolas Bourriaud calls 'relational aesthetics' (1998) or what Claire Bishop (2006: 178-179) famously labeled 'the social turn' in art, referring to artists such as Francis Alÿs, Pierre Huyghe, Matthew Barney, and Thomas Hirschhorn.

\section{The Importance of Professional Discourse in Contemporary Art}

With art's growing autonomy and the freedom to follow its own increasingly specialized agenda, making sense of artworks becomes the domain of specialists who develop sense-making discourse. Sense-making discourse on art takes many forms, from newspaper coverage to longer, in-depth pieces in catalogues of museums and exhibitions to critical discourse in art magazines. From among this variety of art journalism and art criticism, we focus on discourse in specialized magazines - a genre that has its roots in the 18 th century and that attained its present form of critical, in-depth pieces concerned with the work of artists and broader art-world issues by the late 19th century (Elkins, 1996; Helmreich, 2010). Outlets such as The Studio (which became Studio International in 1964), Frieze, and the UK's Art Monthly serve as good examples. They combine an explicitly international agenda with pieces on modern art, architecture, and design. ARTNews, with correspondents such as Danto and Greenberg, and Artforum serve as US pendants. The discursive practices in and content of these journals varies greatly depending on niche, readership, the intellectual allegiance of critics, etc. (Codell, 2001). Yet, underlying this discourse is a vision, however rudimentary, about the nature(s) of art (Osborne, 2004). Although no systematic historical analysis of this discourse is available, a number of characteristics may be identified - characteristics that parallel artistic movements during the 20th century (see Heinich, 1998). Modern art is 
interpreted within the more or less delimited sphere of its own aesthetic functioning, with a focus on artwork and its formal and biographical features. The discursive embedding of contemporary art, on the other hand, is more extensive and more diverse. The meaning of artworks is no longer solely located in the artifacts themselves. Indeed, as Fuchs (2001: 176) remarks, 'the more an art tries to level the distinctions between art and non-art, the more it relies on an esoteric "theory" to explain this very leveling'. While modern art, fixated on developing an aesthetic world of its own, produces discourse that stays close to the formal and aesthetic dimensions of the artworks under examination (see the writings of Clement Greenberg), contemporary art discourse has a much broader scope and highlights political or social/societal aspects - in both content and form - of artistic production. It is because contemporary art is so comprehensive, diverse, and boundless - anything can be art - that the need exists for intermediary institutions that operate as 'translation centers' between producer and consumer. It necessitates the development of social agencies 'who try to bridge the gaps, to soften the impact of artistic adventures and ease the transition to unfamiliar ways of hearing and seeing' (Elias, 1993: 42).

With our analysis of a specialized art magazine, we aim to disclose central topics in contemporary art discourse and empirically explore the centrality of modernist or contemporary themes within the professional discourse on contemporary art over the last 25 years.

\section{Data and Methods}

\section{Frieze}

We chose Frieze as our main data source, as it is a general, mainstream magazine specializing in contemporary art, founded in 1991, and based in London. Frieze publishes eight issues per year and includes essays, reviews, and columns by artists, curators, and columnists on contemporary art and on art-world issues. Its content is also related to a commercial art fair, contains a lot of advertisements, and may be considered somewhat 'conservative' in the sense that it tries to appeal to a broader audience - at least broader than that of the professional discourse meant for a largely academic or strictly artistic readership. Thus, the corpus in our analysis shows similarity to the discourse of other reputed voices within the world of contemporary art, such as Studio International, ARTNews, or Artforum.

When we looked for a general art journal that was representative of contemporary art discourse, we promptly settled on Frieze. Finding a corpus of texts that was digitally accessible and suitable for topic modeling was an accomplishment in itself. With Frieze, we had digital access to all issues and articles, and we analyzed all articles available online from 1991 until May 2015. Consequently, with a corpus that includes 6965 articles (with an average word count of 1029 per article), and with over two million different word forms, we were able to apprehend a lot of variation in relevant discourse within the field of contemporary art. Still, we need to be careful not to make generalizations that are too sweeping, because, by choosing only Frieze, we could not 
cover everything. For example, we could not consider discourse in non-commercial outlets for contemporary art, which may not be similar to the discourse we analyze in Frieze - e.g. catalogues of public museum exhibitions and alternative spaces such as Kunsthallen and Kunstvereins.

\section{Inductively Analyzing Discourse by Means of Topic Modeling}

Topic modeling is an inductive probabilistic method used to analyze a large number of texts (Mohr and Bogdanov, 2013). As mentioned in the introduction, its algorithms look for co-occurrences of words in the corpus, i.e. the collection of documents, and generate 'topics'. These topics can be viewed as lists of words that have a high probability of cooccurring in the articles. Topic modeling is inductive in the sense that it does not depend on observational schemes or active reading of the texts. The input is the corpus; the output is a list of words along with their probabilities of belonging to a certain topic. Topics are like a bag of thematically related words from which authors select words to compose their texts. As most texts about painting will use words like 'canvas', 'paint', and 'color', the documents will likely exhibit a co-occurrence of these words. The articles in the corpus that contain these words, then, are probably related to the topic 'painting'. We use latent Dirichlet allocation (LDA) topic modeling (Blei et al., 2003).

After obtaining lists of words, the researcher's task is to interpret these words as being part of a certain topic. That is, much like factor analysis in 'traditional' statistics, each list (or 'factor') has to be interpreted and labeled. The researcher specifies only the number of topics s/he wants and an alpha parameter, which influences the overlap in topics per document (cf. Jacobi et al., 2015). After reviewing and labeling the topics, the researcher observes the 'topic-per-document' probabilities (TPD), which give an indication of the (mix of) topics related to every article in the corpus. A topic-perdocument probability is the estimated proportion of words in an article that come from a certain topic. So, if TPD is high, the topic is central to the article. If texts are paired with meta-data (such as date, author, source, etc.), it is possible to statistically investigate changes over time or differences in topic usage between authors or sources. To validate the topic-solution generated by the program, we closely examine a number of articles that have the highest probability of having words assigned to a particular topic. In that way, we validate the generated corpus-level topics and can further analyze them through in-depth reading of key texts.

\section{Results}

\section{Number and Nature of Topics}

Our analysis yields 15 different topics, which are presented in Table 1. Words within a topic are arranged according to their centrality to the topic, i.e. the extent to which they go together with the other words in the topic, taking into account their overall dispersion in the corpus. Within each topic, we list the 20 highest-ranked words. To make description easier, we do two things. First, we thematically cluster the 15 inductively generated topics into four groups, linking them to the nature, content, or object(s) of the discourse, 


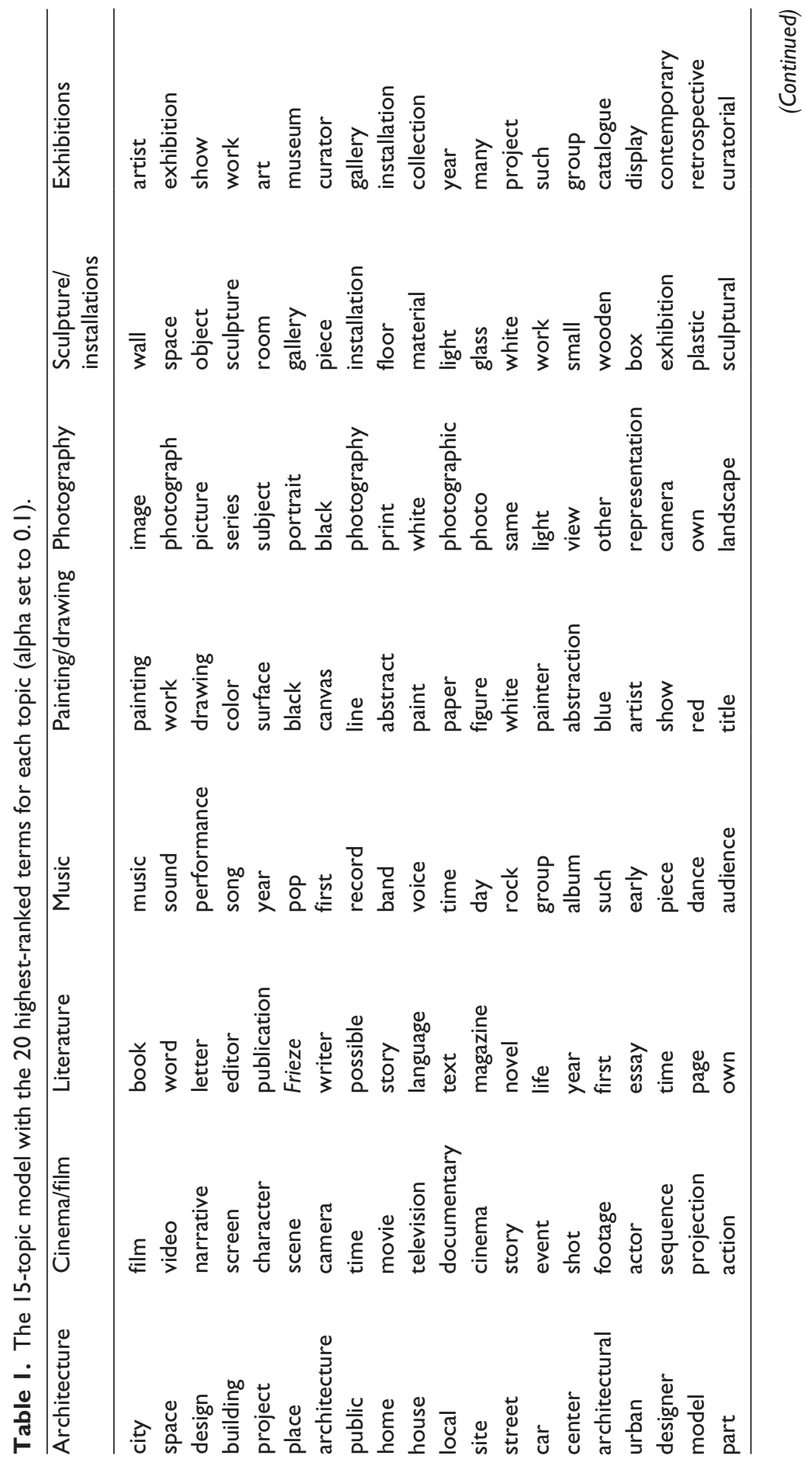




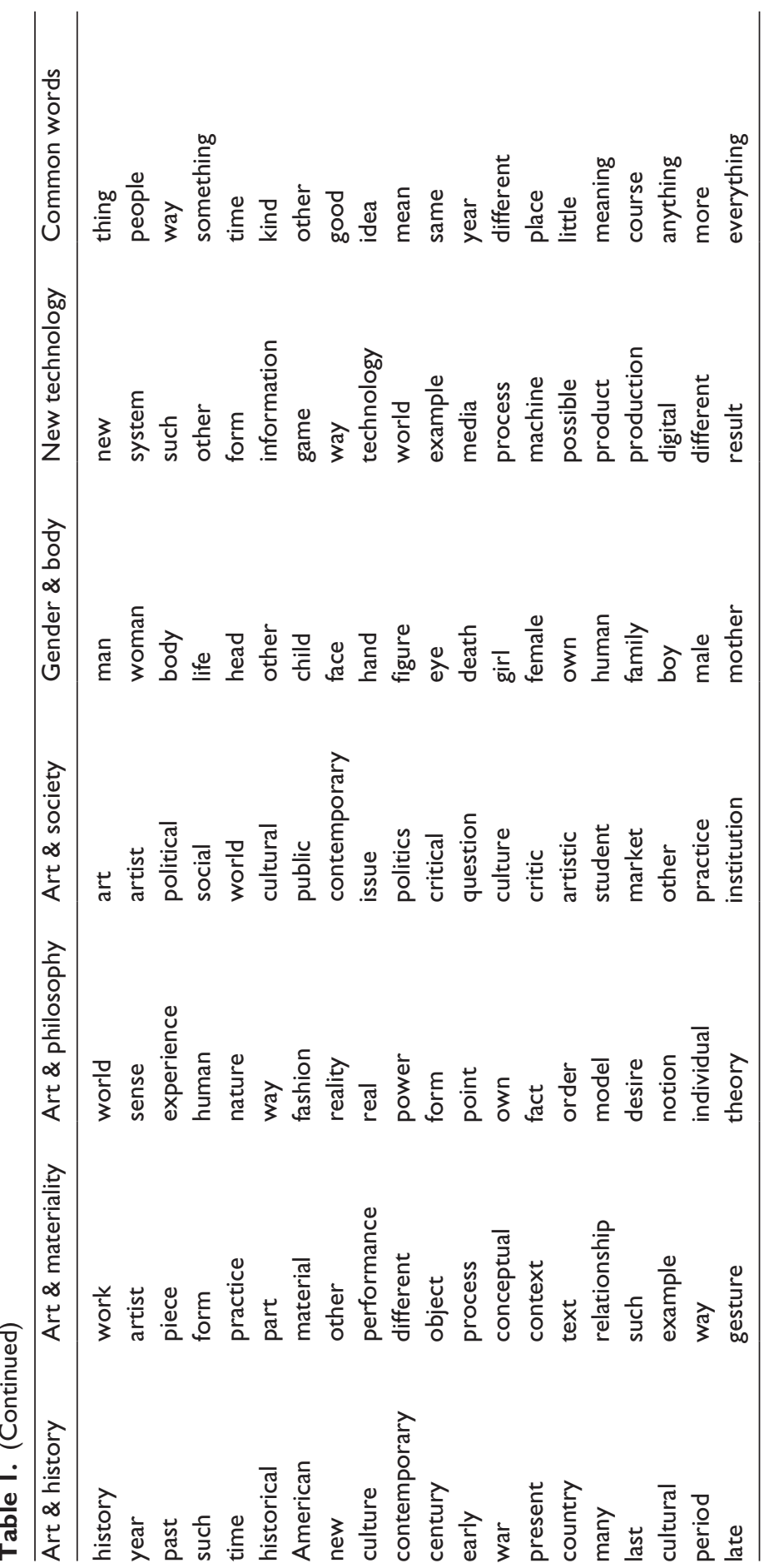


Table 2. Groups of topics by type of content in Frieze.

\begin{tabular}{|c|c|c|}
\hline & Type of content & Description topics \\
\hline I & Media/genres & $\begin{array}{l}\text { Architecture, cinema/film, literature, music, painting/drawing, } \\
\text { photography, sculpture/installations }\end{array}$ \\
\hline 2 & Exhibitions & Previews and reviews of shows \\
\hline 3 & Themes in art & $\begin{array}{l}\text { Art \& history, art \& materiality, art \& philosophy, art \& society, } \\
\text { gender \& body, new technology }\end{array}$ \\
\hline 4 & Common words & - \\
\hline
\end{tabular}

as shown in Table 2. Second, by means of the TPD we look for representative examples of articles that contain certain topics. As mentioned above, a topic-per-document probability indicates how strongly a topic is associated with an article. This serves two purposes. First, it serves as a validation of the topic model: the topics are supposed to be substantively meaningful and consistent variables that are able to get at what they intend to capture. Second, the topics can be deployed as search tools, as means to identify representative texts that can then be used for close reading, for deeper analysis of typical examples. Therefore, topic modeling combines a bird's-eye overview with the potential to ground one's analysis in highly representative textual examples. We cannot go into detail for every topic, but we present examples of the kind of articles that typically and often include particular topics.

The first group includes seven topics and related words representing various media/ genres typical of contemporary art: architecture, cinema/film, literature, music, painting/ drawing, photography, and sculpture/installations. As an example, the topic 'architecture' contains words such as 'city', 'space', 'design', 'building', 'architecture', 'public', 'house', 'local', 'site', 'street', 'project', etc. (topic 1 in Table 1). When we look at the probability of the topic 'architecture' occurring in articles, we see that the article scoring highest, i.e. that contains the most words from that topic, is a piece on Ivrea. This former modernist campus town of the company Olivetti in Italy - an example of an ideal workers' village from the thirties - is now an open-air museum (Issue 99, May 2006). Also scoring high on this topic is the article 'Lux Interior' (Issue 60, June 2001), which deals with the design by Future Systems of the Selfridges building in Birmingham. The article reviews the architectural design elements and their fit with contemporary views on urban planning.

In a domain such as architecture, both formal and societal themes pop up. Looking at articles that typically focus on 'painting', we see a review of the Birmingham exhibition of works by the Cuban 'modernist' painter Carmen Herrera (Issue 126, October 2009). The review talks about vivid colors, free strokes, shapes, pictorial planes, etc., placing her within the tradition of abstract expressionism. In addition, an article on Alex Olson's paintings (Issue 151, November-December 2012) talks about the tools, textures, lines, colors, etc. she uses in her 'modernist, Rothko-esque compositions'. These examples show how this discourse is devoid of social referents and is centered on form and aesthetics.

The same holds for the topic 'sculpture': the article scoring highest on 'sculpture' is a review of a Christoph Weber show. Weber makes minimalist sculptures that 'form a 
narrative with the physical elements of the gallery space' (Issue 147, May 2012). Another article scoring high on sculpture deals with the work of Kitty Kraus. She creates installations with panes of glass and different sorts of optical reflections (Issue 118, October 2008). This demonstrates that Frieze engages with a whole spectrum of media ranging from 'traditional' genres in the plastic arts, such as painting and drawing, to new media of production such as film, video and public-sphere installations, to architecture.

The second group relates to exhibitions. First, it considers the general role of museums in organizing exhibitions, which raises certain questions. How can a museum bring contemporary art to an audience and what kind of factors facilitate or hamper success? And what is the role of curators, for example? Furthermore, it presents reviews, as well as previews, of specific exhibitions, mostly retrospectives, that cover the lives and works of specific artists through interviews, biographical portraits, reviews, etc. (cf. Robertson and McDaniel, 2012). Words that are characteristic of this topic are, for example, 'artist', 'art', 'exhibition', 'work', 'museum', 'catalogue', 'curator', 'collection', 'retrospective', 'display', or 'gallery'. The top article in Frieze (Issue 128, January-February 2010) is 'Looking Forward 2010', which asks 13 curators about their favorite upcoming exhibitions and which partly functions as a promotional device. 'Biennials \& Groups Shows 2009', from the same issue, is similar, but offers more critical assessments.

The third group includes six topics that are typical of discourse on contemporary art. The first two topics, i.e. 'art \& history' and 'art \& materiality', deploy terms typical for art historic and artistic discourse, situating artifacts within the artistic field on the one hand and describing their genesis and formal characteristics on the other, which is indicative of the modernist paradigm. The topic 'art \& history' depicts an (art) historical orientation towards contemporary art, in which both art historic accounts and more forward-looking, utopian perspectives find a place. 'Art \& materiality' focuses on the artifact itself, its materiality, and the context in which it was created. The terminology of the other topics is grounded in domains that are not specifically related to the art field but to fields dealing with political, economic, and/or soci(et)al issues - they use art-external, heteronomous terms. Thus, 'art \& philosophy' deals with ideals of perfection in art and how art comments on and makes sense of la condition humaine or how it fashions our lives, using words such as 'sense', 'world', 'human', 'nature', 'reality', etc. 'Art \& society' centers on the relationship of the arts to political, economic, and social issues. Its discourse critically engages with the position of contemporary art as a vehicle for change in the real world, as a site for critical debate and civic engagement ('art', 'political', 'social', 'public', 'issue', 'critical', 'question', 'market'). For 'art \& society', the top article is 'What the World Needs Now...', a piece in which 22 artists respond to four questions on political art (Issue 87, December 2004). Another piece is titled 'Good Intentions'; it deals with the question of whether recent socially engaged or political art really effects change (Issue 137, March 2011). 'Useful Art' is an interview with Cuban artist and activist Tania Bruguera about what it means not to 'represent politics but to create political situations' (Issue 144, January-February 2012). The topic 'gender \& body' contains words such as 'man', 'woman', 'body', 'figure', 'face', 'head', 'eye', etc. and refers to gender, sexuality, and identity politics in contemporary art. With words such as 'new', 'digital', 'technology', 'information', 'world', 'game', and 'system', the topic 'new technology' reports on the use of new technology and the digital age. 'The Virtual 
Community' (Issue 15, March-April 1994) talks about the Internet and its future, about the freedom of global communication - then (in 1994) a vision of things to come which is now more like a message in a bottle. As can be seen from these few examples, the content of the articles with the highest TDPs clearly reflects the essence of the topics, which serves as a confirmation of their content validity.

The fourth and remaining topic contains common words often occurring together. Also, here the sense-making activity within the discourse is obvious from the co-occurrence of words such as 'idea', 'thing', 'same' or 'different', 'mean', 'meaning', etc.

\section{Evolution of Topics in Frieze}

Figures 1 to 3 show how the topic groups evolve over time. More or less, all media/genres get equal attention in the pages of Frieze - they have a similar probability of occurring, as indicated by the topic-per-document probabilities in Figure 1. We observe that all media/genres revolve around a TDP of about .06. This means that articles have a .06 probability of discussing one of these media/genres-related topics. Media/genres topics such as architecture, film/cinema, literature, music, and photography have slightly less chance of occurring. Painting/drawing and sculpture/installation - the more central genres within the visual arts - are more prominent in Frieze. Some genres have grown in relative importance over time, such as film/cinema, painting/drawing, and sculpture/ installations, but the increase has been modest. Overall, genre topics in Frieze have remained relatively stable over the periods studied.

Figure 2 shows that the (p)reviews of exhibitions have become more prominent over the past 25 years, especially from 2000 onwards. This rise may be related to the role of professional art magazines in publicly announcing upcoming exhibitions to an interested audience - an increase that runs parallel to the quantity of coverage in mainstream newspapers as a result of increased cultural offer (Janssen, 1999). The rise in coverage may also be related to the weight given to professional critics' opinions in making or breaking (the work of) an artist. This resonates with Heinich (2014), who stresses the importance of personality cult in the field of contemporary art. It may also be indicative of Frieze's commercial interests increasing in importance.

Figure 3 presents the evolution of the 'thematic' topics. Like the media/genre topics, the most striking feature is the relative stability of the frequency of their appearance in the pages of Frieze. Both 'art \& history' and 'art \& materiality' remain stable at about .06 TDP. 'Art \& philosophy', 'gender \& body', and 'new technology' show a slightly declining trend. In 1991, they turn out to be the most important topics in Frieze; in 2015 they are the least important. The topic 'art \& society', which involves social and political issues in contemporary art discourse, is characterized by a fluctuating pattern: it decreases in relative importance until 2005, when it picks up, then remaining at about .07. Relative to other 'social' topics, it rises from being one of the least important topics at the beginning of the nineties to by far the most important today with a TDP of .07. The articles scoring highest on this topic all deal with examples of the blending of the social and the artistic. Either art production is done collectively, or it incorporates social themes - such as creating spaces for open communication, depicting, and criticizing the simulacra of the Internet - or it involves the spectator physically in the construction of the artwork. 


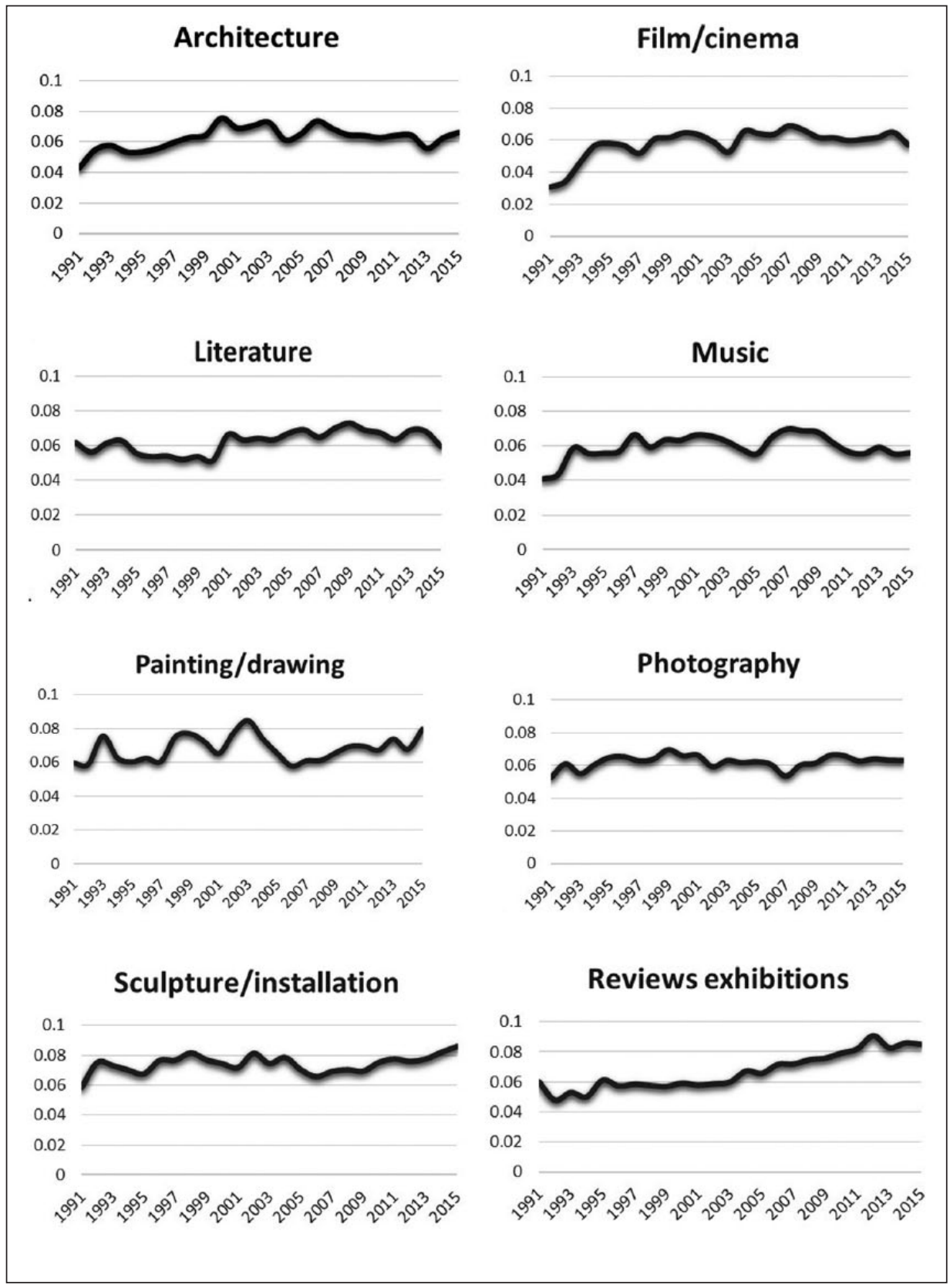

Figure I. Evolution of 'media/genres' topics in Frieze. Scores on the Y-axis are the average per year topics-per-document probabilities. 


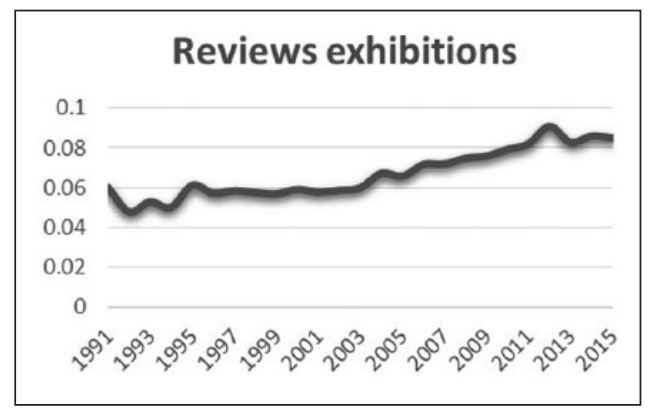

Figure 2. Evolution of 'exhibitions' topic in Frieze. Scores on the Y-axis are the average per year topics-per-document probabilities.

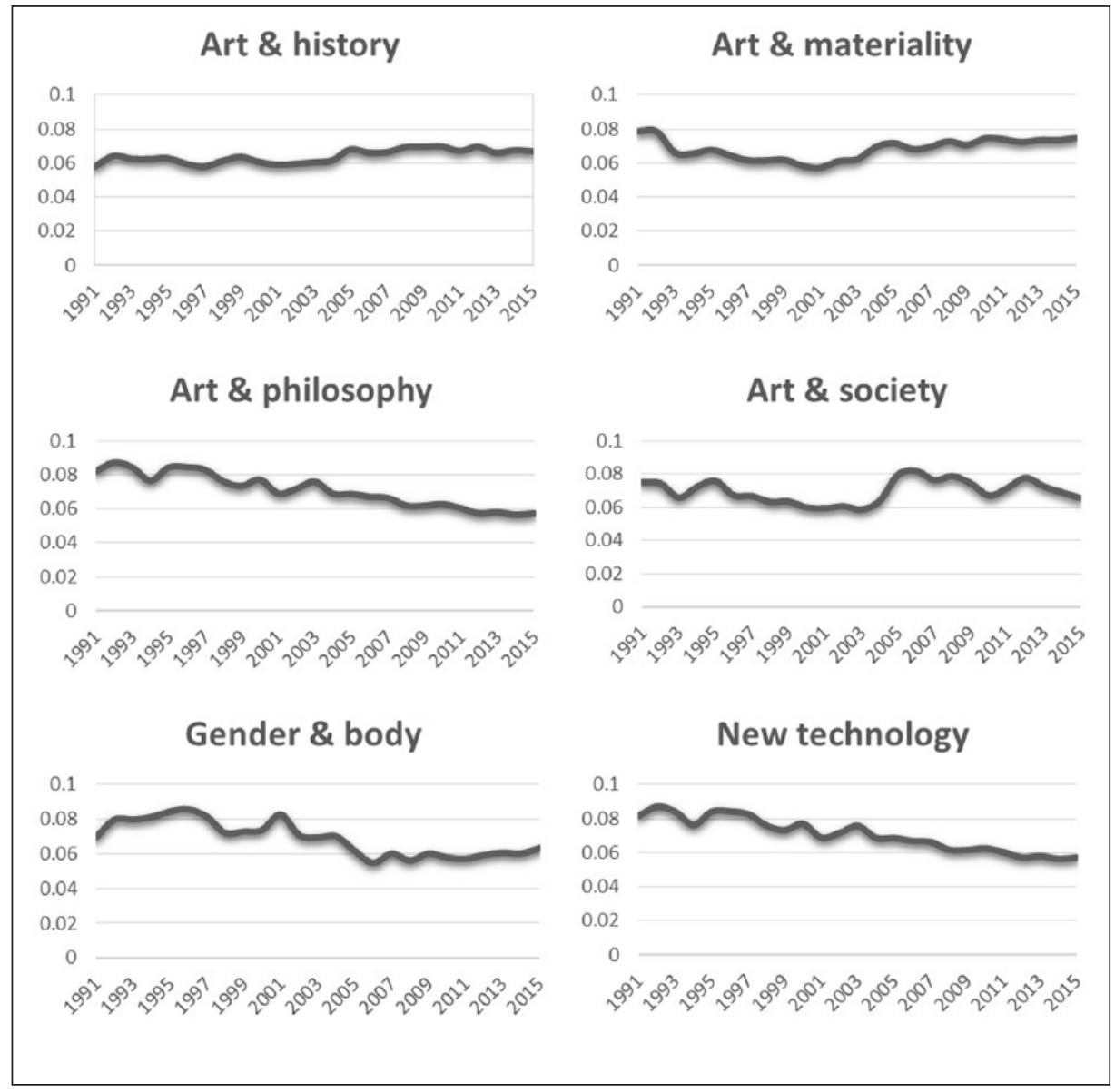

Figure 3. Evolution 'themes/content' topics in Frieze. Scores on the Y-axis are the average per year topics-per-document probabilities. 


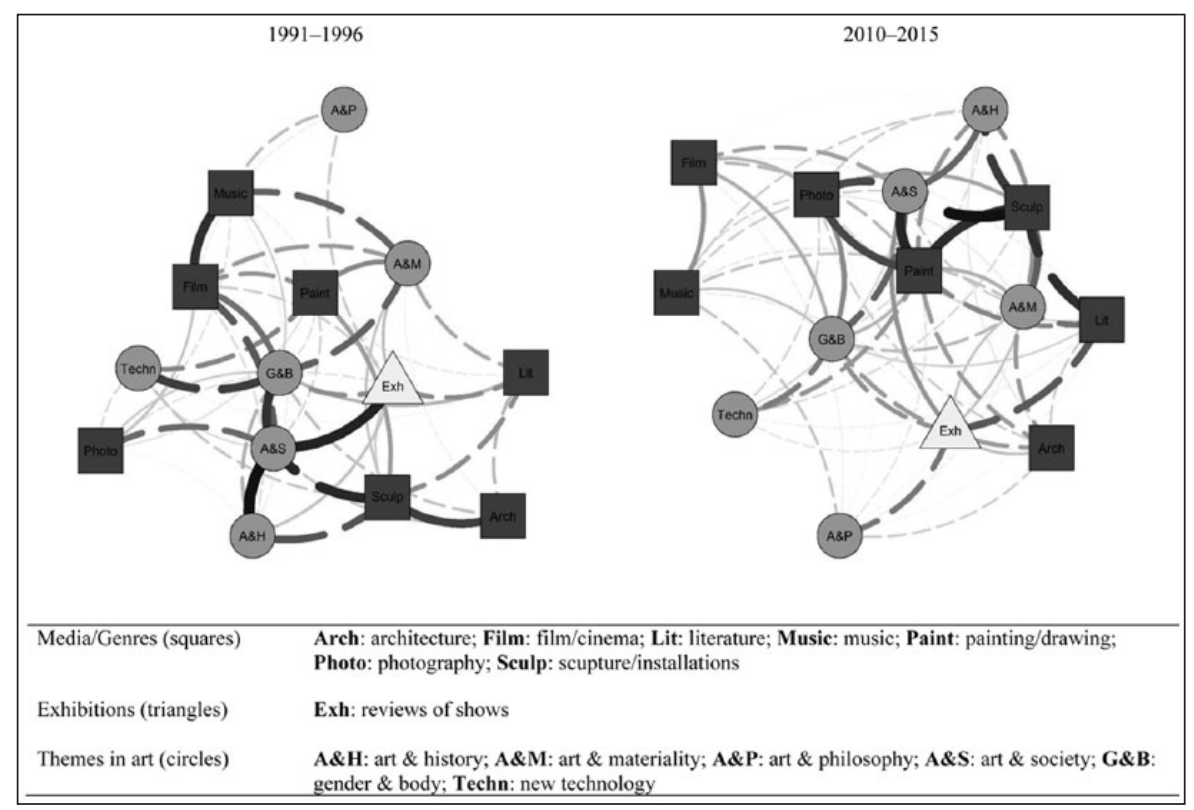

Figure 4. Inter-relationships between the topics.

\section{Inter-Relationships Between Topics}

To explore inter-relationships between topics and changes in these inter-relationships over time, we analyze correlations between topics. To increase interpretability, we visualize these correlations as networks. Nodes correspond to topics and lines represent the correlations between them. Solid lines represent positive correlations and dashed lines negative ones. The width and shade of the lines is proportional to the strength of the correlation: wider and darker lines represent stronger correlations between the topics they connect. We obtained the visualizations - which Figure 4 presents - by using qgraph in $\mathrm{R}$ and by applying the Fruchterman-Reingold algorithm (Epskamp et al., 2012). We present the Spearman's correlations between topics for the years 1991-1996 and 20102015, respectively. We chose to work on journal issues spanning a five-year period because it makes the correlations more robust against small fluctuations (such as special issues), while still allowing for possible evolutions.

The visualizations show that there are no big changes in the inter-relationships between topics over the past 25 years. Overall, media/genre topics do not correlate positively with other genre topics, which indicates that articles tend to focus on specific genres. From 1991-1996, the exceptions are film and music, architecture and sculpture, painting and sculpture. For the period 2010-2015, we observe positive correlations between film and music, sculpture and painting, and photography and painting. Therefore, we address and discuss these genres together in articles.

Articles often mention social (i.e. art \& society) and historical topics (i.e. art \& history) together. Interestingly, these topics do not really pertain to one genre in particular, 
as they have a positive correlation with a variety of genres. There are, however, genres that are less likely to be discussed in terms of social and historical topics. For example, the social and historical topics correlate negatively with sculpture/installations, indicating that articles on this genre rarely address social and/or historical issues. The social topic, however, is correlated positively with (p)reviews of exhibitions, which typically highlight the social/historical content of such (p)reviews in which artifacts are contextualized in place and time. This positive correlation is more pronounced in 1991-1996 than in 2010-2015, which suggests a modest downward trend in the association. This is remarkable, as one would expect that social issues would also become more prominent in the discussion and depiction of museums, exhibitions, and artists.

Unsurprisingly, descriptions of material aspects of artifacts often relate to painting (1991-1996 and 2010-2015) and sculpture/installations (2010-2015). Gender issues cooccur with photography, film/cinema, and music. Literature is an isolated topic that only correlates with gender. Art \& philosophy stands alone. The evolutions that do show up are mostly modest developments. For example, photography often co-occurred with film/cinema in the beginning of the nineties; by 2010, it was more strongly related to painting and sculpture/installations and was unrelated to any societal topic. We argue that this is an indication of the (growing) autonomy and legitimacy of this genre.

\section{Summary of Findings}

To sum up, a diversity of topics characterizes the discourse on contemporary art in Frieze between 1991 and 2015. This discourse deploys art-related language grounded in autonomous principles and focuses primarily on the variety of media/genres and their thematic preoccupations as well as their formal characteristics. Moreover, there are a number of topics pertaining to art-external, societal themes indicative of the social turn. They infuse the field of art with concepts and approaches borrowed from philosophy, politics, history, sociology, economics, etc. There are no dramatic evolutions over time between 1991 and 2015. The same holds for the inter-relationships between topics: there is little evolution in their co-occurrence. The social, philosophical, and historical topics are not related to any genre in particular.

\section{Conclusion and Discussion}

Our article shows that topic modeling is a powerful explorative tool that allows us to systematically analyze large corpora of texts that are digitally available and to inductively arrive at a number of clearly interpretable topics. When linked to metadata, the evolution of topic prevalence can be monitored and inter-relationships between topics can be charted and analyzed. Furthermore, topic modeling allows for locating texts that characteristically contain topic-related words. It serves as a heuristic device to identify texts within the corpus that typically include a certain topic - texts that can then be further interpreted by close reading that digs for deeper meaning and strives to understand ambiguities and to capture dissensus. However, using topic models has its downsides: the need for further interpretation of core texts within a topic is one (cf. Bishop, 2017). Another is finding a digitally available corpus. We selected Frieze partly because of its 
digital availability. By choosing Frieze, we were able to capture only a fraction of the discourse on contemporary art, and we were unable to pick up developments in art criticism prior to 1991. Thus, our analysis remains blind to emerging topics in, for example, public museums' catalogues, publications related to Biennials, Kunsthallen/Kunstvereins, or Internet blogs (cf. Lijster et al., 2015). This represents an important limitation. Yet, the choice for Frieze was well considered, as it represents the type of heterogeneous art discourse found in specialized commercial magazines in the tradition of the Victorian art press (Helmreich, 2010). Moreover, as our corpus spans a period of 25 years, we are confident we have explored a significant part of the professional discourse on contemporary art.

We found that the pages of Frieze contain a wide variety of topics. These topics feed off both artistic and non-artistic domains; they draw from both modernist and contemporary discourses. The attention to (the interpretation of) form and aesthetics is reflected in topics linked to the traditional and the 'new' media of production, such as painting, sculpture/installations, film/cinema, architecture, etc. The process of interpretation of artworks is a classic hermeneutic process (Heinich, 1998: 308-309) and consists of attributing meaning to the artifact by placing it into a genre-specific narrative that better situates its formal aspects, its genesis, its intellectual history, and its meaning ('art \& history' and 'art \& materiality'). Yet, professional art discourse does more. It also links art to philosophical and social ideas. This fosters a previously unseen intellectualization of discourse on art, in which sociologists and philosophers now join the ranks of experts writing on contemporary art - ranks that had previously been largely restricted to art historians (cf. Heinich, 2012).

Interestingly, we found indications of what art historian Claire Bishop has labeled the social turn in contemporary art. She speaks of a 'recent surge of artistic interest in collectivity, collaboration, and direct engagement with specific social constituencies' in which the 'inter-subjective space created through these projects becomes the focus - and mediumof artistic investigation' (Bishop, 2006: 178-179; 2012). We found that this surge is indeed recent: although it has been present in art discourse throughout the past 25 years, the interest in 'art \& society' which peaked in 2005 has continued. It is a distinctly politically and ideologically inspired discourse, in which politics as well as art's relationship to society are thematized. Contemporary art, which has become increasingly aware of its social position and the context in which it is embedded, turns in part to social forms as medium and to political and historical content as inspiration, justification, and legitimation.

This reflexivity characteristic of the social turn parallels what Willem Schinkel calls 'defamiliarizing art' (2010: 284), an echo of Zygmunt Bauman's injunction to 'de-familiarize the familiar'. After the mimetic and auto-referential character of, respectively, classical and modern art, contemporary art's referent is social reality and it critically examines and interrogates reality's taken-for-granted qualities. Contemporary art tackles issues few people would give a second thought to and critically assesses them, discloses their artificial structures, and debunks hidden power relations. According to Schinkel, this makes contemporary artists akin to sociologists. This reflexive discourse also reminded us of Giddens' claim that our world is becoming increasingly sociological - we even find traces of sociology 'feeding-in' to the pages of an art magazine like Frieze. Perhaps this social discourse is inspired by artists becoming increasingly self-aware and 
trying to legitimize their work, not through the production of beauty or the quest for formal innovation - art for art's sake - but through carving out a niche as social critics. A recent piece by Victoria Alexander (2017) explains this shift of the relatively autonomous art world towards a more social, instrumental outlook ('art does more than appeal to the senses') by highlighting the political field's influence through state funding systems. Alexander identifies what she calls 'a Faustian bargain': art organizations, as well as artists, depend on resources provided by the state and hence must justify their funding by highlighting their social functions.

Moreover, because of developments within the field of contemporary art itself, the clear 'modernist' distinction between autonomy and heteronomy has become more complex. Indeed, Bourdieu's characterization of art as 'plagued with ... ideological illusions' (de la Fuente, 2007: 412) - with artists and art consumers denying that extraaesthetic factors influence their respective production and consumption of art - may be true in the ideological and aesthetic framework of modernism. Its application to contemporary art, however, is more problematic. Contemporary art is more self-reflexive; it is art that is aware of Bourdieu's framework and challenges exactly the same things that Bourdieu challenged: the portrayal of the artist as an inspired genius, the existence of 'pure' aesthetics, the illusion of absolutely autonomous art. Some contemporary art overtly involves the social and some artists even explicitly frame their art as a form of research à la Schinkel, as a way of critically engaging with and understanding social reality (for an interesting study of similar developments in contemporary dance, see Laermans, 2015). The tension between autonomous 'art for art's sake' and heteronomous commercial success seems outdated in light of the recent 'social' developments within the artistic field. This perspective resonates with Hanquinet et al.'s claim - made regarding the field of art consumption - that cultural capital needs to be restructured and that form and function need to be supplied with a third dimension, a social/critical one (Hanquinet et al., 2014).

This is not to say that autonomous discourse is waning or disappearing - it is still very much there - but it has to share the stage with heteronomous criteria that favor 'social' judgments and legitimation. The distinction Raymond Williams (1977) makes between dominant culture and residual and emergent culture may prove helpful in accounting for this co-existence of artistic discourse. Each form of discourse may be related to different institutional backgrounds. The academic criteria of beauty and mimesis may have become less important, just as 'les salons' and 'les académies' have become less important. The modernist quest for aesthetic and formal innovation is dominant when the artistic field was at the apex of its autonomy. Encroachment from the state in the artistic field may have given rise to the emergent socially inspired forms and topics in contemporary art discourse. The observed rise of coverage of exhibitions may highlight another encroachment, this time from the market, thus showing the commercial, marketing-thearts side of Frieze.

Our systematic analysis of artistic discourse in Frieze through topic modeling did indeed reveal a discourse in which new 'emergent' social, political, and commercial issues infuse the production and reception of artworks. Yet, 'dominant' autonomous topics related to genres and formal aesthetics remain at least equally important (cf. Elkins and Montgomery, 2013). 


\section{Funding}

The authors received no financial support for the research, authorship, and/or publication of this article.

\section{References}

Alexander V (2003) Sociology of the Arts: Exploring Fine and Popular Forms. Oxford: Blackwell Publishing.

Alexander V (2017) Heteronomy in the arts field: State funding and British arts organizations. The British Journal of Sociology. Epub ahead of print 25 July. DOI: 10.1111/1468-4446.12283.

Arnason H and Prather M (1998) History of Modern Art: Painting, Sculpture, Architecture, and Photography. New York: Harry N. Abrams.

Becker H (1982) Art Worlds. Berkeley: University of California Press.

Bennett T (2007) Habitus clivé: Aesthetics and politics in the work of Pierre Bourdieu. New Literary History 38(1): 201-228.

Bishop C (2006) The social turn: Collaboration and its discontents. Artforum February: 178-183.

Bishop C (2012) Artificial Hells: Participatory Art and the Politics of Spectatorship. London: Verso.

Bishop C (2017) Against digital art history. Paper published on Humanities Futures, a project of the Franklin Humanities Institute at Duke University. Available at: https://humanitiesfutures. org/papers/digital-art-history/ (accessed 22 January 2018).

Blei DM, Ng AY and Jordan MI (2003) Latent dirichlet allocation. Journal of Machine Learning Research 3: 993-1022.

Boltanski L and Thévenot L (1991) On Justification: Economies of Worth. Princeton, NJ: Princeton University Press.

Bourdieu P (1980) Questions de sociologie. Paris: Editions de Minuit.

Bourdieu P (1996) The Rules of Art: Genesis and Structure of the Literary Field. Palo Alto, CA: Stanford University Press.

Bourriaud N (1998) L'esthétique relationnelle. Dijon: Les presses du réel.

Codell J (2001) When art historians use periodicals: Methodology and meaning. Victorian Periodicals Review 34(3): 284-289.

Cools G and Gielen P (eds) (2014) The Ethics of Art: Ecological Turns in the Performing Arts. Amsterdam: Valiz.

Danto AC (2001) Philosophizing Art: Selected Essays. Berkeley: University of California Press.

de la Fuente E (2007) The 'new sociology of art': Putting art back into social science approaches to the arts. Cultural Sociology 1(3): 409-425.

DiMaggio P, Nag M and Blei D (2013) Exploiting affinities between topic modeling and the sociological perspective on culture: Application to newspaper coverage of US government arts funding. Poetics 41: 570-606.

Elias N (1993) Mozart: Portrait of a Genius. Cambridge: Polity Press.

Elkins J (1996) Art criticism. Grove (Oxford) Dictionary of Art. Available at: http://www.jameselkins. com/images/stories/jamese/pdfs/art-criticism-grove.pdf (accessed 5 December 2017).

Elkins J and Montgomery H (eds) (2013) Beyond the Aesthetic and the Anti-aesthetic. The Stone Art Theory Institutes, Volume 4. University Park: Pennsylvania State University Press.

Epskamp S, Cramer A, Waldorp L, Schmittmann V and Borsboom D (2012) Qgraph: Network visualizations of relationships in psychometric data. Journal of Statistical Software 48(4): $1-18$.

Fuchs S (2001) Against Essentialism: A Theory of Culture and Society. Cambridge, MA: Harvard University Press. 
Hanquinet L, Roose H and Savage M (2014) The eyes of the beholder: Aesthetic preferences and the remaking of cultural capital. Sociology 48(1): 111-132.

Hanquinet L and Savage M (eds) (2016) Routledge International Handbook of the Sociology of Art and Culture. New York: Routledge.

Heinich N (1998) Le triple jeu de l'art contemporain: Sociologie des arts plastiques. Paris: Editions de Minuit.

Heinich N (2012) Mapping intermediaries in contemporary art according to pragmatic sociology. European Journal of Cultural Studies 15(6): 695-702.

Heinich N (2014) Le paradigme de l'art contemporain: Structures d'une révolution artistique. Paris: Editions Gallimard.

Helmreich A (2010) The death of the Victorian art periodical. Visual Resources: An International Journal on Images and Their Uses 26(3): 242-253.

Inglis D and Hughson J (eds) (2005) The Sociology of Art: Ways of Seeing. New York: Palgrave Macmillan.

Jackson S (2011) Social Works: Performing Art, Supporting Publics. New York: Routledge.

Jacobi C, van Atteveldt W and Welbers K (2015) Quantitative analysis of large amounts of journalistic texts using topic modeling. Digital Journalism. DOI: 10.1080/21670811.2015.1093271.

Laermans R (2015) Moving Together: Theorizing and Making Contemporary Dance. London: Valiz.

Janssen S (1999) Art journalism and cultural change: The coverage of the arts in Dutch newspapers 1965-1990. Poetics 26: 329-348.

Lijster T, Milevska S, Gielen P and Sonderegger R (eds) (2015) Spaces for Criticism: Shifts in Contemporary Art Discourses. London: Valiz.

Martin B (2005) L'évaluation de la qualité sur le marché de l'art contemporain: Le cas des jeunes artistes en voie d'insertion. Doctoral Thesis in Economics, Université Paris Nanterre, Paris, France.

Milevska S (2006) Participatory art: A paradigm shift from objects to subjects. Springerin. Hefte für Gegenwartskunst February. Available at: https://www.springerin.at/2006/2/partizipatorische-kunst/ (accessed 22 January 2018).

Mohr J and Bogdanov P (2013) Topic models: What they are and why they matter. Poetics 41(6): $545-569$.

Osborne P (2004) Art beyond aesthetics: Philosophical criticism, art history and contemporary art. Art History 27(4): 651-670.

Peterson RA and Anand N (2004) The production of culture perspective. Annual Review of Sociology 30: 311-334.

Robertson J and McDaniel C (2012) Themes of Contemporary Art: Visual Art After 1980, 3rd edn. Oxford: Oxford University Press.

Schaeffer J-M (1992) L'art de l'âge moderne: L'esthétique et la philosophie de l'art du XVIIIe siècle à nos jours. Paris: Gallimard.

Schinkel W (2010) The autopoiesis of the artworld after the end of art. Cultural Sociology 4(2): 267-290.

Tanner J (ed.) (2003) The Sociology of Art: A Reader. London and New York: Routledge.

Taylor C (1992) The Ethics of Authenticity. Cambridge, MA: Harvard University Press.

White HC and White CA (1965) Canvases and Careers: Institutional Change in the French Painting World. Chicago, IL: University of Chicago Press.

Williams R (1977) Marxism and Literature. Oxford: Oxford University Press.

Zolberg V (1990) Constructing a Sociology of the Arts. Cambridge: Cambridge University Press.

Zolberg V (2015) A cultural sociology of the arts. Current Sociology 63(6): 896-915. 


\section{Author biographies}

Henk Roose is Associate Professor at the Department of Sociology (Ghent University, Belgium). His current research focuses on the link between cultural participation and social stratification using geometric data analysis and the analysis of historical shifts in artistic discourse using archival data.

Willem Roose is Master in Sociology (Ghent University, 2009) and Master in Graphic Arts (School of Arts Ghent, 2012). He is interested in theoretical perspectives on (contemporary) visual arts.

Stijn Daenekindt is a Postdoctoral Researcher affiliated with Ghent University and Erasmus University Rotterdam. He holds a Master's in Statistics (KU Leuven, 2012) and a PhD in Sociology (Ghent University, 2015). His interests lie in the fields of cultural sociology and political sociology.

\section{Appendix}

Generally, a number of preliminary steps are taken to get a corpus ready for topic modeling. The first step we took was to lemmatize the corpus, i.e. to keep only nouns, adjectives, and verbs to create the document term matrix. As a second step, we filtered this document term matrix by keeping only terms with a relative frequency of more than five percent. We ran topic modeling on this filtered corpus only in the third step. We explored the solution with 15 topics using alpha $=50 / \mathrm{k}$ (normal benchmark). Then we re-ran the same model with alpha $=5 / \mathrm{k}$ (see Jacobi et al., 2015): the topics retained similarity. When we reduced or increased the number of topics, we saw that we either lost information (e.g. photography clusters with film; gender \& body disappears; art \& history clusters with other topics) or obtained interpretable topics that were uninteresting/irrelevant from a theoretical point of view. Thus, 15 topics is, from a substantial viewpoint, a good number of topics for maintaining an elegant balance between interpretability and maximum information. 